\title{
Attachment and reflective function: Their role in self-organization
}

\author{
PETER FONAGY AND MARY TARGET \\ Sub-Department of Clinical Health Psychology, University College London
}

\begin{abstract}
The paper traces the relationship between attachment processes and the development of the capacity to envision mental states in self and others. We suggest that the ability to mentalize, to represent behavior in terms of mental states, or to have "a theory of mind" is a key determinant of self-organization which is acquired in the context of the child's early social relationships. Evidence for an association between the quality of attachment relationship and reflective function in the parent and the child is reviewed and interpreted in the context of current models of theory of mind development. A model of the development of self-organization is proposed which has at its core the caregiver's ability to communicate understanding of the child's intentional stance. The implications of the model for pathological self-development are explored, with specific reference to the consequences of maltreatment.
\end{abstract}

The "self" and concepts allied to it are currently experiencing a considerable revival of interest from social scientists and developmentalists (e.g., Bracken, 1996; Cicchetti \& Beeghly, 1990; Cicchetti \& Toth, 1994). Psychological interest in the self is usually traced to James' $(1890,1892)$ distinction of two aspects of the self, the "I" (self as subject) and the "Me" (self as object). The I is the active agent responsible for constructing the self-concept of Me. To paraphrase in the terms of current cognitive neuroscience, the $\mathrm{Me}$ is the mental representation, while the I embodies the mental processes or functions which underpin representations of the self (Mandler, 1985). The I organizes and interprets experience, ensures the experience of

We gratefully acknowledge the support of the Gatsby Foundation and the Ludowyk Trust. We would also like to acknowledge the long-term collaboration with Miriam and Howard Steele and, more recently, Juliet Holder. We are particularly grateful for the creative suggestions of Gyorgy Gergely. We benefited very much from the helpful editorial suggestions of Dante Cicchetti.

Address correspondence and reprint requests to: Peter Fonagy, Sub-Department of Clinical Health Psychology, University College London, Gower Street, London WC1E 6BT, UK; E-mail: p.fonagy@ucl.ac.uk. continuity through time, creates a sense of freedom or initiative, and generates the experiences leading to the distinctness of oneself as a person. Modern developmental psychology has brought us closer to a full understanding of the mental processes which combine to organize the representation of oneself.

\section{Reflective Function}

Developmentalists over the past 10 years have drawn attention to the remarkable capacity of young children to interpret their own and other people's behavior in terms of mental states. Reflective function is the developmental acquisition that permits the child to respond not only to other people's behavior, but to his ${ }^{1}$ conception of their beliefs, feelings, hopes, pretense, plans, and so on. Reflective function or mentalization enables children to "read" people's minds (e.g., Baron-Cohen, Tager-Flusberg, \& Cohen, 1993; Morton \& Frith, 1995). By attributing mental states to others, children make people's behavior mean-

\footnotetext{
1. For economy of expression only, we will generally use "he" to refer to a child and "she" to refer to a parent or other caregiver.
} 
ingful and predictable. As children learn to understand people's behavior, they can flexibly activate, from multiple sets of self-other representations organized on the basis of prior experience, the one(s) best suited to respond adaptively to particular interpersonal transactions.

The interdependence of reflective function as it applies to others and to the self was highlighted by the second pioneer of psychological self theory, Cooley (1902/1964): "The thing that moves us to pride and shame is not the mechanical reflection of ourselves, but an imputed sentiment, the imagined effect of this reflection upon another's mind" (p. 153). Developmentally, this may be thought to imply that a mental operation is required in early childhood, to derive the self-state from the apperception of the mental state of the other. Exploring the meaning of others' actions is then a precursor of children's ability to label and find meaningful their own psychological experiences. This ability arguably underlies the capacities for affect regulation, impulse control, self monitoring, and the experience of self-agency, the building blocks of the organization of the self. In previous papers (e.g., Fonagy, Steele, Moran, Steele, \& Higgitt, 1991a) we have labeled the predisposition to understand behavior in mental state terms reflective self-function, or more simply reflective function.

The notion of reflective function is rooted in Dennett's $(1978,1987)$ proposal that three stances are available in the prediction of behavior: the physical stance, the design stance, and the intentional stance. Dennett's thesis is that explanation in terms of beliefs and desires, so-called intentional states, provides good grounds for predicting human behavior-the only grounds accessible to all of us; this knowledge is embodied in the theory of mind of folk psychology (see Churchland, 1986; Mele, 1992). ${ }^{2}$

Theory of mind is an interconnected set of beliefs and desires, attributed to explain a person's behavior. The theory of mind concept

2. Dennett's formulation is unnecessarily restrictive (Bolton \& Hill, 1996). It does not address predicting the behavior of systems which do not function rationally. has great generalizability and explanatory value. Recent philosophers of mind (Hopkins, 1992; Wollheim, 1995) have extended Dennett's approach to unconscious processes. They illustrated that one of Freud's most substantive contributions was to extend folk psychology to unconscious mental states, a theory of unconscious mind, thus making those aspects of behavior meaningful which-using the ordinary constructs of intentionalitymake little sense (e.g., dreams, neurotic symptoms, humor). These behaviors may be understood if we add unconscious beliefs, thoughts, and feelings to our everyday model of the mind.

Extending these ideas, we consider reflective function to be the mental function which organizes the experience of one's own and others' behavior in terms of mental state constructs. Reflective function concerns knowledge of the nature of experiences which give rise to certain beliefs and emotions, of likely behaviors given knowledge of beliefs and desires, of the expectable transactional relationships between beliefs and emotions, and of feelings and beliefs characteristic of particular developmental phases or relationships. Its essence is not that the individual should be able to articulate this theoretically, and this is clear in our operationalization (Fonagy, Steele, Steele, \& Target, 1997). Individuals differ in the extent to which they go beyond observable phenomena to explain their own or others' actions in terms of beliefs, desires, plans, and so on. This undoubtedly high level cognitive capacity is, we believe, an important determinant of individual differences in self-organization, intimately involved with many defining features of selfhood such as self-consciousness, autonomy, freedom, and responsibility (Bolton \& Hill, 1996; Cassam, 1994). Intentional stance, in the broad sense considered here (i.e., including apparently irrational unconscious motives), explains one's own behavior and therefore creates the continuity of self-experience which is the underpinning of a coherent self-structure.

It is important that reflective function is not conflated with introspection. Bolton and Hill (1996) note that the weakness of introspection is to define mental states in terms of 
conscious motivation rather than, as here, in terms of their capacity to regulate behavior. Introspection or self-reflection is quite different from reflective function as the latter is an automatic procedure, unconsciously invoked in interpreting human action. We see it as an overlearned skill, which may be systematically misleading in ways much more difficult to detect and correct than mistakes in conscious attributions would be. Reflective function similarly lends a shape and coherence to self-organization which is outside awareness, in contrast to introspection, which has a clear impact on experience of oneself.

Our central concern here is the acquisition of reflective function and the light this might cast on the development of self-organization. Baron-Cohen and Swettenham (1996) appropriately ask "... how on earth can young children master such abstract concepts as belief (and false belief) with such ease, and roughly at the same time the world over?" (p. 158). Their answer is that of modularity theorists, along the lines of Chomsky's solution to the problem of the acquisition of a knowledge of syntax. They postulate an innate (learning) mechanism with a specific location in the brain (see also Leslie, 1994; Segal, 1996). Other current psychological theories stress the cognitive precursors of theory of mind. Some favor the folk psychology, theory-theory, approach assuming that the child evolves a scientific theory-like network of interdependent propositions about the mind on the basis of experience (e.g., Botterill, 1996; Gopnik, 1996). Others assume that theory of mind is acquired via simulation of the mental state of the other, either through making inferences from what we ourselves would do in the imagined circumstances (e.g., Goldman, 1993; Harris, 1992) or an even more radical assumption of imagined transformation into the other which does not involve introspection or inference (Gordon, 1995).

Both simulation and theory-theory models may appear to emphasize social learning aspects of the development of mentalization but, upon closer scrutiny, their focus is at the level of mechanism rather than content. They question how and when the child acquires knowledge of other minds in an abstract sense and do not ask what the child feels about the mental states he encounters in others. Yet, in this context at least, the question of knowledge and that of emotional investment are evidently closely related. The child may know what the other feels but care little or not at all about this; alternatively this information, for some youngsters, may be an issue of survival. The emotional significance of mental states determines the evolution of the capacity or structure available for processing, but this is not usually addressed. In current models of theory of mind development the child tends to be seen as an isolated processor of information, engaged in the construction of a theory of mind using biological mechanisms which may fail if the child's endowment is poor.

This, from the viewpoint of developmental psychopathology and its psychosocial treatment, is a barren picture which ignores the central role of the child's emotional relationship with the parents or other caregivers in fostering the capacity to understand interactions in terms of mental states. The development of children's understanding of mental states is embedded within the social world of the family, with its interactive network of complex and at times intensely emotionally charged relationships, which, after all, constitute the primary content of early reflection. Therefore it should not surprise us that the nature of family interactions, the quality of parental control (Dunn, Brown, Somkowski, Telsa, \& Youngblade, 1991b), parental talk about emotions (Denham, Zoller, \& Couchoud, 1994), and the depth of parental discussion involving affect (Dunn, Brown, \& Beardsall, 1991a) are all strongly associated with the acquisition of the intentional stance in observational studies. The involvement of the family in the child's acquisition of a theory of mind is further highlighted by the robust finding that the presence of siblings in the family appears to improve the child's performance on a range of false-belief tasks (Jenkins \& Astington, 1996; Perner, Ruffman, \& Leekman, 1994; Ruffman, Perner, Naito, Parkin, \& Clements, in press).

Modular accounts of theory of mind development have some difficulty with such data. Both the theory-theory and the simulation ac- 
counts also fall short of adequately addressing the social origins of this critical aspect of selforganization. In the theory-theory account mental concepts are thought to develop within a network of interdependent concepts on the basis of data from the social world, but the social world does not generally "give" concepts to the child - it provides him with data for concept building. In the simulation model mental state concepts are thought to arise from introspection, but this begs the question of how children come to think of their own mental states in terms of feelings, beliefs, wishes, and so on. This paper attempts to explore the role of parent-child relationships in the transformation of prereflective experience of mental states into reflective understanding of them. Within this social context both social models of mentalization may have their place; the predominance of one or other route to understanding the mind may be a function of individual differences between children and between environments, but, in our view, a satisfactory model must have the child's relationships with attachment figures as its starting point.

\section{Developmental Roots of Reflective Function in Infancy}

\section{“Teleological” stance}

There is general agreement that self-organization initially entails the integration of bodyrelated experiences, defining the physical boundaries of self and world (e.g., Brownell \& Kopp, 1991). Once the physical self is established, social exchanges, the identifications of social boundaries and, somewhat later, the identification of social causality become central self-functions. The caregiver's recognition of the child's intentional stance, however, is communicated nonverbally, beginning at birth. Between birth and 5 months, face-to-face exchanges of affective signals between infant and caregiver (Beebe, Lachmann, \& Jaffe, 1997; Tronick, 1989) play a key role in the development of the child's representation of affect.

For example, using a microanalytic observational paradigm, Beebe, Lachmann and
Jaffe (1997) have shown that interaction between baby and mother shows both self-regulation and sensitivity to the state of the other. Their facial expressions showed rapid fluctuations: affect, space, and degree of contact in each $1 / 12 \mathrm{~s}$ time period responded to the expression of the other in the previous period, presumably on the basis of schemata of anticipated reactions. High coordination predicted later good cognitive performance, whereas lower levels of coordination were optimal for secure attachment and easy temperament. Interestingly, security with the mother in the Strange Situation at 1 year was better predicted by coordination with a stranger than with the mother at 4 months.

Interactions at this stage may be argued to be presymbolic, in the sense that they are nonmentalistic; the infant is not required to represent the thoughts or feelings of the caregiver. However, they involve reference to future states such as goals as explanatory constructs in the interpretation of the behavior of the other. Thus they can be used to predict behavior although these structures would be limited in their capacity to modify behavior. Recent experimental work by Gergely and Csibra (e.g., Gergely, Nadasdy, Csibra, \& Biro, 1995) suggests that the infant's perception of social contingencies by the second half of the $1 \mathrm{st}$ year is teleological in that they make reference to future states (goals) as explanatory entities in the interpretation of behavior based on the principle of "rational action." The teleological stance is applied by infants to human and nonhuman objects alike. Studies by Gergely and Csibra (1997) demonstrated that infants express surprise when nonhuman but moving objects (such as various sized discs in a computer-generated animated display) appear to act "irrationally"- not choosing the optimal action given specific goals and reality constraints. The infant is assumed to extend teleological models beyond the prediction of human behavior. Teleological models, however, evolve into mentalizing ones in the restricted domain of human action. They become fully mentalizing once representations of goal states come to be thought of as desires, and constraints come to be thought of in terms of the agent's beliefs about physical reality. 
The infant's behaviors in dyadic interactions are underpinned by an evolving model of rational action by the caregiver. We would argue that the development from teleological to mentalizing models will depend upon the quality of interpersonal interactions between the infant and the caregiving adult. It should be noted that although such models may merely represent rational action, it is the perceived rather than actual rationality of an act which defines the teleological model. Thus misapprehension of reality constraints (e.g., assumed dangerousness) will provide and create a model where action which is clearly irrational from an external standpoint is nevertheless seen as based on the principle of rational action. The predictive significance of the infant's response to a stranger in the Beebe study suggests that representations (working models) of self-other relations even when not yet mentalized begin to vary in quality in the 1 st year, and this quality is related to infantcaregiver interactions, as observed in the lab situation. If sufficiently coherent to be generalized to other relationships in characteristic ways, they may index processes crucial to the creation of a secure mother-infant bond.

\section{Representational mapping}

Representational mapping is likely to underpin the gradual move in infancy from teleological to mentalizing models of mind. Between 6 and 18 months the child becomes increasingly able to match his mental state with that of the caregiver vis-à-vis a third object or person, as, for example, in requesting or joint attention (Bretherton, 1991). The communication is evidently deliberate, since children at this phase try to repair failed communicative bids and thus show some recognition of awareness and agency in self and other including affective states, perceptions, and intentions (Stern, 1985; Wellman, 1993). Neisser (1991) suggested that based on perceptual processes, two preconceptual aspects of the self emerge: the ecological and the interpersonal. While the former involves self-awareness in reference to perception of nonsocial surroundings, the latter is generated via the coperception of actions of the self and related contingent actions of others. Taking Stern's (1985) and Neisser's formulation of the interpersonal self together, we can identify three aspects of the intersubjective development of the self, which Mundy and Hogan (1994) term instrumental action states, sensory or perceptual action states, and affective action states. Rogers and Pennington (1991) offered a model of the cognitive underpinnings for such an intersubjective process in their concept of representational mapping (the process of coordinating representations of self and other) which is thought to underlie the sharing of affect, attention, and higher order aspects of cognition such as beliefs. The existence of imitation skills from the neonatal stage represents strong evidence for the model (Meltzoff, 1993). The acquisition of an appreciation of mental states, however, goes beyond mirroring.

The development of an understanding of affect in self and other may be a good illustration of the role of representational mapping in the development of reflective abilities (Gergely \& Watson, 1996; Target \& Fonagy, 1996). Anxiety, for example, is for the infant a confusing mixture of physiological changes, ideas, and behaviors. When the mother reflects, or mirrors, the child's anxiety, this perception organizes the child's experience, and he now "knows" what he is feeling. The mother's representation of the infant's affect is represented by the child and is mapped on to the representation of his self-state. The discrepancy between these is helpful insofar as it provides organization for the self-state and thus the caregiver's mirroring can become the higher order representation of the child's experience. Within this model mirroring would be expected to fail if it is either too close to the infant's experience or too remote from it. If the mirroring is too accurate, the perception itself can become a source of fear, and it loses its symbolic potential. If it is unavailable, or is contaminated with the mother's own preoccupation, the process of self-development is profoundly compromised. We may presume that individuals for whom the symptoms of anxiety signify catastrophes (e.g., heart attack, imminent death, etc.) have metarepresentations of their emotional responses which can- 
not be limited in intensity through symbolization, perhaps because the original mirroring by the primary caregiver exaggerated the infant's emotions.

Admittedly this is a speculative model, but it is empirically testable. It might help answer the thorny question of why individuals with panic disorders attribute immense significance to physiologically relatively mild levels of disequilibrium. The suggestion here is that the metarepresentation, or symbolic representation, of affect in these cases contains too much of the primary experience; hence, instead of labeling the experience having the potential to attenuate it, it tends to stimulate and exacerbate symptoms of the affect state, which in turn accentuates the secondary expression, in a cycle of escalating panic. ${ }^{3}$ In collaboration with George Gergely, we are designing a series of studies of the infant's emotional understanding which will more directly test these ideas. In a recent study (Fonagy et al., 1995), we have confirmed that mothers who soothe their distressed 8-montholds most effectively following an injection rapidly reflect the child's emotion, but this mirroring is mixed with other affects (smiling, questioning, mocking display, and the like). In displaying such "complex affect" (Fónagy \& Fónagy, 1987) they ensure that the infant recognizes their emotion as analogous to, but not isomorphic with, their experience and thus the process of symbol formation may begin. In this way, the representational mapping between affect of self and emotions of others, the exchange of affect between young child and caregiver, provides a unique source of information to the child about his own internal states.

We suggest that the meaning or sense of affect develops out of the integrated representation of the affect in self and other. The combination of the representation of self-experience and the representation of the reaction of the caregiver elaborates the child's teleological model of the mind, and ultimately enables him to interpret and understand affective dis-

3. In terms of linguistic theory, one may say that the signifier is not sufficiently "demotivated"; in other words it resembles the signified too closely. plays in others as well as arriving at the regulation and control of his own emotions. The representational mapping of emotion displays and self-experience is seen here as a prototypical instance of caregiver sensitivity, which, as we shall attempt to demonstrate, is likely to be an important component of the development of mentalizing. The sensitivity of the caregiver prompts the child to begin organizing self-experience according to clusters of responses which will eventually come to be verbally labeled as specific emotions (or desires). The high contingent response is the means by which this mapping can take place. The child's affective experiences are given further meaning by becoming associated with clusters of reality constraints within the parent-infant interaction (leading to rudimentary beliefs about the causes and consequences of his emotional state).

\section{Transmission of attachment security}

The attachment system (Bowlby, 1969, 1973, 1980 ) is intimately connected with the process of representational mapping and the development of the reflective function of the self. There is general agreement that, as the self exists only in the context of the other, the development of the self is tantamount to the aggregation of experiences of self in relationships (e.g., Crittenden, 1994; Sroufe, 1990). Psychoanalytic object relations (Kernberg, 1982; Winnicott, 1965) and attachment theorists (Bowlby, 1980) are in agreement that repeated, invariant aspects of self-other relations are abstracted into internal representational mental models and structured, to use Kernberg's term, into self-other-affect triads, or internal working models, according to Bowlby. Although in its original formulation the concept of internal working model lacked specificity (Dunn, 1996), more recent empirical work by psychoanalysts has greatly improved this (Horowitz, 1995; Luborsky \& Luborsky, 1995).

At the same time, cognitive scientists have elaborated the notion of procedural memories based on the nonconscious implicit use of past experience (e.g., Johnson \& Multhaup, 1992; Schacter, 1992). There is general agreement 
that the memory system is at least of a dual nature with two relatively independent, neurologically and psychologically homogeneous, systems underpinning it. In addition to the autobiographical memory, which is at least in part accessible to awareness, an important component to memory is a nonvoluntary system which is implicit, principally perceptual, nondeclarative, and nonreflective. It is possible that it is, at least in certain respects, more dominated by emotional and impressionistic information than its autobiographical counterpart (e.g., van der Kolk, 1994). It stores the "how" of executing sequences of actions, motor skills being prototypical instances. The procedural knowledge that it contains is accessible only through performance. It manifests itself only when the individual engages in the skills and operations into which knowledge is embedded. Given these features, it seems likely that the schematic representations postulated by attachment and object relations theorists are most usefully construed as procedural memories, the function of which is to adapt social behavior to specific interpersonal contexts.

The classification of patterns of attachment in infancy (Ainsworth, Blehar, Waters, \& Wall, 1978) taps into procedural memory (Crittenden, 1990; Fonagy, 1995). The strength of the Strange Situation (SSn) as a method of psychological assessment is to provide a powerful analogue of past situational contexts within which knowledge concerning the "how" of behavior with a specific caregiver is accrued. In this sense attachment is a skill, one which is acquired in relation to a specific caregiver encoded into a teleological model of behavior. In the London Parent-Child Study, the Adult Attachment Interview (AAI), administered before the birth of the first child to 100 predominantly middle class primiparous parents, was tested as a predictor of attachment classification at 1 year to mother and at 18 months to father (Fonagy, Steele, \& Steele, 1991b). There was only a marginally significant association between the attachment classification with mother and that with father. However, both SSn results were powerfully predicted by the attachment classification of the respective parent on the AAI (Steele,
Steele, \& Fonagy, 1996). The small overlap between the two sets of classifications could be equally well accounted for by assuming a temperament factor or by the generalization of the child's behavior with the mother (reflecting her attachment classification) to his behavior with the father. The results suggest that the infant develops independent models (self-other schemata) for his major attachment relations based on his past history of interactions with each of those individuals. In turn, these interaction experiences are indexed by the caregiver's representation of her or his attachment history.

There has been considerable research on the manner in which representations of attachment might influence the caregiver's behavior with the child. Van IJzendoorn's (1995) comprehensive meta-analysis identifies a "transmission gap," to the extent that the variability which AAI narratives and SSn classifications share is not accounted for by observational data concerning the sensitivity of caregiver behavior. Indeed, studies of the AAI-SSn association, which concurrently measured the sensitivity of caregiver-infant interaction, have yielded negative (Ward \& Carlson, 1995) or inconclusive results (van IJzendoorn, Kranenburg, Zwart-Woudstra, Van Busschbach, \& Lambermon, 1991). Previously, we have suggested that the transmission gap may be a consequence of the limitations of measures of sensitivity (Fonagy et al., 1995). Sensitivity is a generic construct covering a wide range of parental behaviors (Belsky, Rosenberger, \& Crnic, 1995). Not all of these may be equally powerful in engendering secure attachment. If secure attachment is conceived of as the acquisition of procedures of goal oriented rational action for the regulation of aversive states of arousal within relationships (Cassidy, 1994; Sroufe, 1996), it is argued that these would be most consistently acquired and coherently represented when the child's acute affective state is accurately, but not overwhelmingly, reflected back to the child.

The child who looks for a way of managing his distress identifies in the response of the caregiver a representation of his mental state which he may internalize and use as part of a higher order strategy of affect regulation. 
The secure caregiver soothes by combining a "mirror" with a display incompatible with the child's affect (thus perhaps implying coping). This formulation of sensitivity has much in common with the British psychoanalyst, Wilfred Bion's (1962) notion of the role of the mother's capacity to mentally "contain" the affect state intolerable for the baby, and respond in terms of physical care in a manner that acknowledges the child's mental state yet serves to modulate unmanageable feelings. The finding that the clarity and coherence of the mother's representation of the child mediates between her attachment status and her behavior is certainly consistent with this model (Slade, Belsky, Aber, \& Phelps, in press). Ratings of the quality of the reflective function of each caregiver were found independently to predict the child's security of attachment in the London Parent-Child Project (Fonagy et al., 1991a).

If secure attachment is the outcome of successful containment, insecure attachment may be seen as the infant's identification with the caregiver's defensive behavior. Proximity to the caregiver is maintained at the cost of a compromise to reflective function. A dismissing (Ds) caregiver may altogether fail to mirror the child's distress because of the painful experiences this evokes for her or because she lacks the capacity to create a coherent image of the child's mental state. By contrast, the preoccupied (E) caregiver may represent the infant's state with amplification and insufficient marking, or complicated by responses to the parent's ambivalent preoccupation with her own experience, so much so that the symbolic potential of the exchange is lost. In both cases the infant internalizes the caregiver's attitude and "this dysynchrony becomes the content of the experience of the self" (Crittenden, 1994, p. 89).

\section{Infant attachment and developing self}

We may speculate about the impact of this on the development of the child's sense of self. We know that avoidant infants respond to separation with minimal displays of distress while experiencing considerable physiological arousal (Spangler \& Grossman, 1993). Crit- tenden (1988; Crittenden \& DiLalla, 1988) reports that maltreated toddlers display falsely positive affect which does not match their true feelings. At an extreme, the internalization of the caregiver's defenses can not only lead to a failure to adequately represent and display actual emotional experience, but also to the construction of an experience of self around this false internalization (Winnicott, 1960).

While the experience of "putting on an act" may be common, particularly in adolescence (Harter, Marold, Whitesell, \& Cobbs, 1996), here we are referring to the highly distressing experience of personality disordered children who feel a sense of alienation from their core self (Bleiberg, 1994). A strategy many such children adopt later in development is to attempt to externalize this false part of their self-representation, and manipulate the behaviors of others around them so these match the incongruent self-representation. We would argue that this explains the strangely coercive behavior with the caregiver of preschool children whose attachment in infancy was classified as disorganized (Crittenden, 1992; Main \& Cassidy, 1988). In a desperate way they try, we suggest, to provoke behavior in another person which expresses part of their self-representation experienced as "alien," they can then experience a more coherent residual self (Fonagy \& Target, 1995).

\section{Secure infant becomes mentalizing child}

There is general agreement that the "harmoniousness of the mother-child relationship contributes to the emergence of symbolic thought" (Bretherton, Bates, Benigni, Camaioni, \& Volterra, 1979, p. 224). Bowlby recognized the significance of the emergence of "the child's capacity both to conceive of his mother as having her own goals and interests separate from his own and to take them into account" (1969, p. 368). Moss, Parent, and Gosselin (1995) reported that attachment security with mother was a good concurrent predictor of metacognitive capacity in the child in the domains of memory, comprehension and communication. The Separation Anxiety Test, a projective test of attachment security, has been shown to be a good predictor of be- 
lief-desire reasoning capacity in 3- to 6-yearold children when age, verbal mental age, and social maturity were all controlled for (Fonagy, Redfern, \& Charman, 1997).

We have recently completed a prospective study of the relationship of attachment security to mother (1 year) and father (18 months) and children's performance on three tests of theory of mind at 5 years (Fonagy, Steele, Steele, \& Holder, submitted). Ninety-two of 96 children tested in the SSn at 12 and 18 months were seen. Eighty-two percent of those classified as secure at 12 months with mother passed the belief-desire reasoning task, whereas $46 \%$ of those who had been classified as insecure failed. Infant-father attachment (at 18 months) also predicted the child's performance, with $77 \%$ of infants classified as secure passing the test compared to $55 \%$ of children classified as insecure. There was some indication of an additive relationship, in that $87 \%$ of children with two secure relationships passed the belief-desire task, $63 \%$ of those with only one secure relationship and only $50 \%$ of those insecure with both did so. A similar but somewhat weaker pattern could be observed with the second-order false-belief task. Thirty-six percent of those secure with both parents passed compared with $23 \%$ who were secure with one and $9 \%$ who were insecure with both.

In a somewhat smaller but careful longitudinal study of mother-infant dyads, Meins and colleagues (Meins, Fernyhough, Russel, \& Clark-Carter, in press) reported that $83 \%$ of children who were securely attached in infancy passed a false-belief task at age 4, in comparison with $33 \%$ of insecurely attached peers. At age $5,85 \%$ of securely attached children and $50 \%$ of insecurely attached ones passed a task requiring an understanding of information access. Although, probably because of its small sample, the study was not able to replicate our results on the false belief and emotion task, the general trend of the findings confirms that security of attachment is significantly linked to symbolic abilities in general and precocious mentalizing in particular.

There are both trivial and substantive explanations which could account for these findings. They would be trivial if the association of secure attachment and false belief understanding was due to an as yet unknown and unmeasured third factor, such as temperament. More plausibly, it could be argued that the facilitative effect of secure attachment is due to a more relaxed, task-oriented attitude, a general facility to engage in a cognitively demanding task, to relate to an adult experimenter in a playful, exploratory way, and so on: that it reflects performance, rather than competence. This suggestion could be tested using a false-belief task where implicit and explicit knowledge of false belief is separately assessed. If attachment security relates to performance, then securely attached children would be expected to do better only on the explicit (verbal/pointing) task. Implicit, procedural false belief reasoning would be expected to be facilitated by secure attachment only if this was associated with superior reflective capacity. This study remains to be performed, and is planned in our laboratory. In what follows we shall, however hazardously, assume that the relationship between false belief reasoning and security of attachment is nontrivial.

We then envisage two alternative sets of models to explain this relationship: (a) Security of attachment in infancy predisposes children to benefit from social processes directly facilitating reflective abilities and social understanding (mediational models), and (b) security of attachment is an indicator of that quality of infant-caregiver relationship which generates psychological understanding. In this second model, the social processes which accelerate the mentalizing quality of self-organization are the very same as those which ensure security of attachment.

Mediational models would require that specific social processes are shown to be involved in this aspect of the development of self-organization, and such social processes are enhanced in securely attached individuals. There are at least three candidates which meet these criteria.

The first is pretense. There is evidence that children in their 3rd year who engage more readily in cooperative interaction (Dunn et al., 1991b), and specifically in joint pretend play (Astington \& Jenkins, 1995; Youngblade \& 
Dunn, 1995), show superior mentalization and emotion understanding performance. There is a separate body of observations from longitudinal studies of attachment that preschool children securely attached to their mother in infancy engage more strongly in fantasy play than avoidant children, whose engagement is low and whose pretend play is impoverished (e.g., Belsky, Garduque, \& Hrncir, 1984; Bretherton et al., 1979; Main, Kaplan, \& Cassidy, 1985). There is also evidence that securely attached young children can more easily use help from adults to elaborate their play (Meins et al., in press; Slade, 1987).

It is highly plausible that joint pretend play or playfulness fosters the understanding of mental states. Deliberate role-taking is seen as integral to the off-line simulation model of the performance of mentalization tasks (Goldman, 1989). Within other models pretend play is an early manifestation of the theory of mind mechanisms (Leslie, 1987). It is an important puzzle why 3-year-olds can understand that someone is entertaining a pretend representation but not a false belief (Harris, Kavanaugh, \& Meredith, 1994), a pretend/real distinction but not an appearance/reality one (Flavell, Flavell, \& Green, 1987). In the case of pretend, the representations, while they are different from reality, are shared by those engaged in the pretend game. As Astington (1996) put it, "they are intermental, not intramental" (p. 193). The sharing of representations different from reality may help in understanding situations where representations are not only different from reality but are not shared in a social pretend domain. In joint pretend play or playfulness the adult adopts the child's mental stance and re-presents it to the child in relation to a third object which is symbolically held in mind by both (Target \& Fonagy, 1996). The scaffolding provided by the child's playmate in pretend play (Vygotsky, 1967) not only promotes earlier success but is also the mechanism whereby the development of reflection comes about. Lillard (1993) argued that symbolic play may offer a "zone of proximal development" for the skills which subserve mentalization ability. Children with a secure attachment history may be more likely to engage in an activity which presumes a degree of trust, in so far as the child relies on the other's version or perception of reality.

The second is talking. There is evidence that conversations about feelings and about the reasons behind people's actions are linked to the relatively early achievement of reflective function (Dunn \& Brown, 1993). Threeyear-olds whose mothers spontaneously explained their emotions in a lab task showed enhanced emotion understanding over the subsequent 15 months (Denham et al., 1994).

Patterns of mother-child interaction characteristic of secure dyads - shared play, comforting, or joking - are also contexts within which mothers' explanations of mental states are particularly found to facilitate reflective function (Dunn, 1996). Secure attachment may then engender patterns of verbal interaction between child and caregiver which in turn support thinking about feelings and intentions.

The central role of language in the acquisition of mentalizing capacity was forcefully advanced by Smith (1996), using primate evidence. Even more pertinent is Harris's (1996) proposal that the experience of engaging in conversations per se shows children that people are receivers and providers of information, whether or not the conversation refers to mental states. The structure of informative conversations (e.g., being told about an event one has not witnessed, dissent and denial, filling in information gaps) implies that partners in a conversation differ in what they know and believe about a shared topic. Effective conversation requires that gaps in shared knowledge and belief are acknowledged and addressed. The measurement of attachment in adults (Main, Kaplan, \& Cassidy, 1985) emphasizes that secure attachment involves greater sensitivity to the rules of conversation.

The third potential mediator is peer group interaction. We have already noted that interaction with siblings enhances theory of mind performance. There is an independent body of evidence which supports a strong link between secure attachment in infancy and ratings of peer competence: social orientation, reciprocity, popularity, and empathy (e.g., Elicker, Englund, \& Sroufe, 1992; Park \& Waters, 1989). 
Both simulation theory and theory-theory explanations of the development of mentalization offer good explanations of the facilitative effect of more intense peer group interaction (Ruffman et al., in press). Peer group interaction should increase the opportunities the child has for simulation, imagining what he would see, think, feel etc., if he were in another person's situation. Equally, interaction with peers or older sibs could be seen from a theory-theory perspective as a rich source of ideas about how the mind works. An alternative view may be that enculturation is itself the source of the child's mental state concepts (Astington, 1996). Bruner (1983) proposed that parents' tendency to treat the infant's spontaneous gestures as if they were intentional communications leads to infants seeing themselves as having intentions and starting to communicate intentionally. The social world (in the first instance, the parent) fosters the child's sense of his mental self through complex linguistic and interactional processes, behaving towards the infant in a way that leads him eventually to share the assumption that his own behavior and (by simulation or the observation of similar interactions between the caregiver and others) that of others may be best understood in terms of mental states (Fonagy \& Target, 1996; Target \& Fonagy, 1996). Through participation in activities of their culture they come to share their culture's way of understanding people's actions. If there is a process of "apprenticeship" in which peers and caregivers encourage the child's use of mentalizing concepts (Astington, 1996), then secure attachment may be a catalyst to this learning process. The greater readiness with which secure children are willing to explore and engage with the social world could then account for their mentalizing skill.

There is nothing exclusive about these three mediational models. Pretense often involves the use of mental state language. Interaction with peers often involves both language and pretense. In general, social engagement tends to enhance social understanding, and such engagement is more accessible to securely attached children. There is, however, a problem with a singular model. Evidence from Dunn's work suggests that these different contexts correlate poorly with one another (Dunn, 1996). For example, observational data shows that individual differences found in pretend play, management of conflict, and talking about mental states are not correlated between social situations (mothers, siblings, close friend) although each correlates with sociocognitive assessments (e.g., Youngblade \& Dunn, 1995). These findings could suggest that there are a number of independent, simultaneous pathways between attachment, social situations, and social cognition.

Alternatively, there is the second possibility, that the suggested mediating variables are not on the causal path at all, that their correlation with the rate of acquisition of mentalization is spurious, that this facility is directly related to the child's attachment status. Early experience with the caregivers in the 1st year of life may create a bedrock of theory of mind competence, helping the child to move from a teleological to a mentalizing model of behavior. What evidence do we have to support such a contention?

First, recall that Fonagy, Steele, Steele, and Holder (1997) found that a mother's attachment classification before the birth of the child was a powerful predictor of the child's theory of mind competence at 5 years. Although, on the face of it, this can be accounted for by the mediational models, we believe that there is now evidence that the caregiver brings something to the parentchild relationship, evident even before the birth, which may be critical in the child's establishment of both secure attachment and mentalization.

What is this capacity? It is well established that in infancy, mothers of securely attached children are more sensitive to their children's needs (Ainsworth, Bell, \& Stayton, 1971; Isabella, 1993). We have already mentioned that the parent's capacity to envision the mental states of her or his own parents is predictive of the infant's security of attachment to each parent (Fonagy et al., 1991a). In a follow-up of the same group, the same capacity also predicted superior performance on a false belief task at 5 years, controlling for verbal fluency in the child. (However, this result was not 
found for all tasks which could be thought to index mentalization).

A path analysis of the above data showed that not all the variance predicted was mediated by mother-infant attachment status at 1 year. Mother's mentalizing ability seemed to have a direct as well as an indirect relationship with the child's theory of mind. Thus, the child's attachment security was not the only predictor; the mother's tendency to envision people (including the child) as mental entities also seemed to be important.

The above data suggest that common mechanisms underpin attachment organization in caregiver and infant, and the precocious emergence of mentalizing in the child. It should be remembered that no clear causal path was identified among mediational models. The relative importance of various potential mediational mechanisms for the attachment-theory of mind relationship varies according to context but intergenerational data may be consistent with at least two of the models (pretense, language). Further experimental research which manipulates parental behavior and explores attachment and theory of mind task performance (van IJzendoorn, Juffer, \& Duyvesteyn, 1995) will be necessary to show whether specific behaviors which engender secure attachment simultaneously enhance mentalizing. For such a study to be feasible, we need a model of how attachment may directly relate to theory of mind performance. Next we outline a tentative model of how such a mechanism may operate.

\section{Reflective parenting and development of mentalization}

We take the view that the acquisition of the theory of mind is part of an intersubjective process between the infant and caregiver (see Gopnik, 1993, for a highly elegant elaboration of such a model). In our view, the caregiver facilitates the creation of mentalizing models through complex linguistic and quasilinguistic processes, primarily through behaving towards the child in such a way that leads him eventually to see that his own behavior may be best understood by assuming that he has ideas and feelings which determine his actions, and the reactions of others to him, which can then be generalized to other similar beings. The caregiver approaches the crying infant with a question in her mind: "Do you want your nappy changed?" "Do you need a cuddle?" The sensitive caregiver is unlikely to address the situation without having the person in mind, so is unlikely to say to herself, "Are you wet around your bottom?" or "Have you been standing alone too long?" The sensitive caregiver can bridge the focus on physical reality and internally directed attention, sufficiently for the child to identify contingencies between internal and external experience. Ultimately, the child arrives at the conclusion that the caregiver's reaction to him may be understood as rational given the assumption of an internal state of belief or desire within himself. Unconsciously and pervasively, the caregiver ascribes a mental state to the child with her behavior, treats the child as a mental agent, which is perceived by the child and used in the elaboration of teleological models, and then in the development of a core sense of mental selfhood. We assume that this, by and large, is a mundane process, happening routinely throughout early life, not reflected on, and so rarely modified. Caregivers, however, differ in their ways of carrying out this natural human function. Some may be particularly alert to the earliest indications of intentionality; others may need stronger indications before perceiving the child's mental state and modifying their behavior accordingly. Others, as we described in the context of early infancy, may systematically misperceive the child's states of mind, with resulting deformation of the child's sense of himself.

The child's development and perception of mental states in himself and others thus depends on his observation of the mental world of his caregiver. He is able to perceive mental states, to the extent that his caregiver's behavior implied such states. This he does when the caregiver is in a shared pretend mode of playing with the child (hence the association between pretend and early mentalization), and many ordinary interactions (such as physical care and comforting, conversations with peers) will also involve such shared menta- 
tion. This is what makes mental state concepts such as thinking inherently intersubjective; shared experience is part of the very logic of mental state concepts.

The parent's capacity to observe the moment to moment changes in the child's mental state, then, lies at the root of sensitive caregiving, which is viewed by attachment theorists as the cornerstone of secure attachment (e.g., Ainsworth et al., 1978; Grossmann, Grossmann, Spangler, Suess, \& Unzner, 1985; Isabella \& Belsky, 1991). Secure attachment in its turn provides the psychosocial basis for acquiring an understanding of mind. The secure infant feels safe in making attributions of mental states to account for the behavior of the caregiver. By contrast the avoidant child to some degree shuns the mental state of the other, while the resistant child focuses on his own state of distress to the exclusion of close intersubjective exchanges. Disorganized infants may represent a special category; hypervigilant of the caregiver's behavior they use all cues available for prediction and may be acutely sensitized to intentional states, and thus may be more ready to construct a mentalized account of the caregiver's behavior. We would argue (see below) that in such children mentalization may be evident but it does not have the central and effective role in self-organization which characterizes securely attached children.

We believe that most important for the development of mentalizing self-organization is that exploration of the mental state of the sensitive caregiver enables the child to find in her mind an image of himself as motivated by beliefs, feelings, and intentions, in other words, as mentalizing. There is considerable evidence to support the view that secure attachment enhances the development of inner security, self-worth, and autonomy (e.g., Londerville \& Main, 1981). Disorganized infants, even if they acquire the skill of mentalization, fail to integrate this with their self-organization. There may be a number of linked reasons for this: (a) The caregiver of the disorganized infant is less likely to be reliably contingent in responding to the infant's selfstate, and further to show systematic biases in her perception and reflection of his state; (b) the mental state of the caregiver evokes intense anxiety through either frightening behavior suggesting malevolence towards the child, or behavior suggesting fear, which may include fear of the child himself; and (c) the child needs to use disproportionate resources to understand the parent's behavior, at the expense of reflecting on self-states.

These factors combine, perhaps, to make disorganized infants become keen readers of the caregiver's mind under certain circumstances, but (we suggest) poor readers of their own mental states. Thus, in terms of the rival models of theory of mind development, such children may acquire a theory-theory of mind, but cannot use simulation of mentalizing with the same confidence as children whose attachment (albeit insecure) is organized. The alternative models may be more usefully thought of as alternative routes to mentalization, the first (theory-theory) accessible to all, the second (simulation) more readily available to children whose early attachment relationships made such a strategy safely possible.

\section{Theoretical model of development of mentalization}

In previous papers (Fonagy \& Target, 1996; Target \& Fonagy, 1996), we have attempted to describe the normal development of reflective function in the child of $2-5$ years. We suggested that there is a transition from a dual mode of experience to mentalization. Primarily from a clinical perspective, we advanced a number of propositions concerning the development of the psychological part of the self. These were

1. Until 3 or 4 years of age, reflective function is characterized by two modes of relating internal experiences to the external situation: (a) In a serious frame of mind, the child expects the internal world in himself and others to correspond to external reality, and subjective experience will often be distorted to match information coming from outside ("psychic equivalence mode"), (e.g., Gopnik \& Astington, 1988; Perner, Leekam, \& Wimmer, 1987); and (b) while involved in pretend play, the child knows that internal ex- 
perience does not reflect external reality (e.g., Bartsch \& Wellman, 1989; Dias \& Harris, 1990), but then the internal state is thought to have no relationship to the outside world ("pretend mode").

2. Normally, the child then integrates these alternative modes to arrive at mentalization, or reflective mode, in which mental states can be experienced as representations. Inner and outer reality can then be seen as linked, yet they are accepted as differing in important ways, and no longer have to be either equated or dissociated from each other (e.g., Gopnik, 1993). Mentalization comes about through the child's experience of his mental states being reflected on, for instance through secure play with a parent or older child, which facilitates integration of the pretend and psychic equivalence modes, through a process which may be an elaboration of the complex mirroring of the infant by the caregiver. In playfulness, the caregiver gives the child's ideas and feelings (when he is "only pretending") a link with reality, by indicating the existence of an alternative perspective, which exists outside the child's mind. The parent or older child also shows that reality may be distorted by acting upon it in playful ways, and through this playfulness a pretend but real mental experience may be introduced.

3. In traumatized children, intense emotion and conflict lead to a partial failure of this integration, so that aspects of the pretend mode of functioning become part of a psychic equivalence manner of experiencing reality. This may be because where maltreatment or trauma has occurred within the family, the atmosphere tends to be incompatible with the caregiver "playing with" the most pressing aspects of the child's thoughts; these are often disturbing and unacceptable to the adult, just as they are to the child. The rigid, controlling behavior of the preschool child with a history of disorganized attachment is thus seen as arising out of a partial failure on the part of the child to move beyond the mode of psychic equivalence in relation to specific ideas or feelings, so that he experiences them with the intensity that might be expected had they been current, external events.

\section{Reflective function and self-development}

While mentalization may not be an unequivocally positive experience, Dunn's work shows us at any rate that the understanding of emotion at 3.5 years predicts a positive perception of social relations, mature moral sensibility, and the understanding of complex emotions (Dunn, 1996). Stern (1985) pointed out that a sense of ownership of one's actions, whether derived from the experience of forming plans, proprioceptive feedback, or the objective consequences of physical actions on the environment, contributes to the sense of self-agency. In our view, such agency also crucially depends on the quality and reliability of reflective function, as ownership of action is intimately tied to the mental state (belief or desire) which initiated it. It is impossible to conceive of self-agency as fully established by the physical actions of the child, as such a large proportion of these will fail to achieve their intended objective, because of the child's immature physical and cognitive capacities. The recognition of the child's intentional stance by others must then be critical in making the thought "real" for the child. We believe that interaction which links perceptions, thoughts, and emotions as causes and consequences of action, and the contemplation of mental states without fear, contribute significantly to self-agency. The earliest foundation is presumably the baby's sense that he brings about the caregiver's mirroring behavior (Gergely \& Watson, 1996).

Of course, the core of self-agency must originally lie with the body, where the infant's attempts to exercise control frequently succeed after early infancy. Higher level, more complex actions, particularly those which involve others in the child's life, often require the reflective caregiver to make sense of the young child's wishes and translate these into action sequences for the links between mental states and action to be established. It is to be expected then that individuals who have experienced severe neglect or coercive, rigid, frightening, and, at an extreme, abusive parenting will frequently experience their sense of self-agency as massively curtailed, and 
limited to the more firmly established bodily (physical) domain.

\section{Reflective function and pathological self-development}

The model of the development of mentalizing capacity which we propose has considerable clinical implications, a few of which we will mention here.

Impact of maltreatment on reflective function. Maltreated children, perhaps even more than insecure ones, are at risk of failing to find their own intentional being within the mind of the caregiver, and are thus at risk of poor development of mentalization. There is accumulating evidence that maltreatment does impair the child's reflective capacities and sense of self. Schneider-Rosen and Cicchetti (1984, 1991) noted that abused toddlers showed neutral or negative affect on recognizing themselves in the mirror, unlike their nonabused peers. Beeghly and Cicchetti (1994) showed that toddlers with a history of maltreatment were not retarded in receptive language but were significantly behind in productive language, reflecting a withdrawal from social interactions. Their specific deficit was in the relative absence of internal state words and the context-bound (concrete) nature of their internal state language. They also showed less differentiation in attributions. Their internal state language was particularly sparse in terms of words pertaining to cognition and belief states, but was richer for perception and desire. Cicchetti and Beeghly (1987) found that young school-age children who had been maltreated used proportionally fewer words about internal states, attributed their internal states to fewer social agents, and were more context bound than their counterparts who were not maltreated. They appeared to control their anxiety by modifying their language to exclude certain aspects and contexts associated with maltreatment. This pattern of results suggests that maltreatment may cause children to withdraw from the mental world. For maltreated children, physical experiences probably become more important, and this may par- adoxically drive them physically closer to a potential abuser. Their ability to adapt to, modify, or avoid the perpetrator's behavior is also constrained by limited mentalizing skills.

There are several reasons why the family environment of maltreatment is likely to undermine the development of reflective function.

First, in abusive families the public world of school and community-where reflective function is common and desirable-is often kept very separate from the world of home, where the inhumane behavior of an adult makes recognition of the mental state of the other dangerous to the developing self. Even where a maltreated child benefits from sensitivity and reflectiveness in his public world, so developing an alternative model of relating and experiencing himself, the models derived from public and family experiences are likely to be kept insulated from each other, and rigid in their application to the separate contexts.

Second, the child may have specific problems in dealing with different experience. In abusive families the meaning of intentional states may be denied or distorted. Abusive parents may claim beliefs and feelings at odds with their behavior. Abuse, particularly within the family, prevents the child testing and modifying representations of mental states. Thus, the mental representation of ideas tends to become rigid, maladaptive, and inappropriate, and consequently may be partially or largely abandoned.

A third possibility is that the maltreated child is forced to construct a model of the caregiver's mind based on an awareness of analogous mental states in himself. It may be argued, on the basis of the simulation model, that simulation is compromised by both the dissimilarity between the child's mental experience and that of the abuser, and the threat that such simulation inevitably brings with it. If understanding the behavior of his caregivers requires the maltreated child to try to generate their probable thoughts and feelings, then he will be confronted with attitudes towards himself which are extremely painful to recognize: hatred, cruelty, indifference. Abuse could destroy the child's belief that one can 
understand others through one's own feelings (Herman, 1992), and the child would be likely to inhibit his capacity for simulation in intense attachment relationships.

A fourth possibility is that the difficulty is not a result of the maltreatment itself, but of the family atmosphere surrounding it (which may well also occur where maltreatment does not). Social constructivist ideas concerning the development of mentalization (e.g., Astington, 1996) are pertinent here. Authoritarian punishment of bad behavior and demanding of obedience is clearly less facilitating of the child's development of mentalization than are equivalent interactions with authoritative parents, who reason with the child and explain decisions and rules with reference to people's different points of view (Baumrind, 1971). There is some evidence that authoritarian parenting is associated with delayed false belief task performance (Holmes, Roldan, \& Miller, 1994, cited in Astington, 1996). As, in a Vygotskian framework, the individual's competence originates in their social interactions and is then internalized, we would expect the abnormal patterns of parent-child relations in the families of maltreated children to lead to a distorted experience of minds. Alessandri (1991, 1992) noted that the incompetence of maltreated youngsters in pretend symbolic play was mirrored by their mothers' difficulty in taking a playful stance with their child, directing their attention, and engaging in positive interactions. This pattern of results is consistent with the model that the lack of appropriate social scaffolding may undermine the normal development of mentalizing in maltreated children.

Developmental framework for abnormal reflective function. It is tempting to argue that disorders of conduct and borderline states can be explained as dismissive and preoccupied forms of nonmentalizing self-organizations respectively, but this would be simplistic. In both instances, there are often variations across situations, or types of relationship. The delinquent adolescent is aware of the mental states of other gang members and the borderline individual is at times hypersensitive to the affective states of mental health profes- sionals and family members. These anomalies can be clarified by more sophisticated developmental theory.

Our chosen framework is provided by "dynamic skills theory" (Fischer \& Farrar, 1987; Fischer, Kenny, \& Pipp, 1990) which depicts development as the elaboration of increasingly complex control systems (skills). Reflective function may be readily conceived of as one such control system, critical to the organization of the self. Within dynamic skills theory, reflective function would be seen as not simply a property of the person, but of the person and situation together, because all skills are composed of both the person's activities and the contexts within which these occur. Particular tasks, specific events, other people, as well as culture are seen as part of the skill. Further, the development of a skill is not seen as progression along a singular path, determined by maturation. Rather, reflective function, as a skill, evolves through varied pathways, molded by many dynamically interacting influences, such as the individual's emotions, social interaction, family relationships and environment, important social groups, the reactions of the wider social world, etc. (Fischer, Knight, \& Van Parys, 1993).

Reflective function is a strand within the developmental web, one of the many distinct control systems that are neither strongly connected with each other, nor coordinated or integrated (Fischer \& Pipp, 1984). The "fractionation" or splitting of all abilities as a function of tasks and domains is well demonstrated, and we might expect reflective function to be subject to the same kind of developmental décalage (unevenness) which characterizes the rest of cognitive development (Flavell, 1982). Fractionation refers to the tendency for a person not to coordinate skills or experiences that are naturally separate, but may be thought of as belonging together by some external criterion (Fischer \& Ayoub, 1994). Just as the understanding of conservation of liquid does not generalize to conservation of area, reflective capacity in one domain of interpersonal interaction should not be expected to generalize to others. Reflective function does not begin as a general capacity, but is a particular skill tied to the 
task and domain where it is learned, a specific category of relationship. Reflective function as a skill may be more or less present in situations as a function of contextual support and emotional state, which push an individual up or down a developmental strand. We have noted above that the child's observed use and experience of mental state language can differ markedly across social contexts. It is clearly possible for task-based skills such as reflective function to come to be coordinated, but this should not be seen as automatic. Unevenness across situations is likely to remain prevalent even in adults, especially when they are emotional (Fischer \& Ayoub, 1994).

Normal development is from fractionation towards integration, which involves the coordination of previously separate skills and provides the foundation for more complex, sophisticated control systems (Bidell \& Fischer, 1994). Abnormalities of reflective function, the continued use of a teleological rather than a mentalizing model for predicting behavior, should not then be seen as either a consequence of arrest and fixation at an early stage, or a regression to that stage. Pathologies in the reflective function of the maltreated child may be expected to develop increased complexity with age and time, in a manner similar to other skills. The skill for limited reflectiveness developed by the child to anticipate and forestall maltreatment and its painful physical and psychological impact would be adaptive in their original world, but would be expected to produce sophisticated forms of difficulty rather than straightforward adaptations in other contexts (Noam, 1990). The ability to be reflective in general, but to show only minimal reflectiveness in the context of one's own childhood and parents, or in specific relationships which reactivate the same schemata, could be a result of natural fractionation. Unevenness or splitting of reflective ability could also be the consequence of an active (purposeful, conscious, or unconscious) attempt on the part of the individual not to coordinate or generalize reflective function to specific relationship domains. Here the unevenness is a developmental achievement, in that the person must create a coordination in order actively to keep separate contexts which would naturally move toward integration. The family might of course, as we mentioned, support such splits with sharp dissociations between their public, proper world and their private, tyrannical one. The split is context and affect dependent; within an attachment theory framework we might say that the self is organized so that certain internal working models include considerable reflective componentsexpectations incorporating the mental states of self and other-while other working models of relationships appear impoverished, indicating only minimal mentalizing skills. In the latter contexts the subject will offer only stereotyped, concrete, low level descriptions. This does not imply developmental delay or regression; rather it suggests a remarkably complex ability to coordinate two distinct levels of functioning. The abusive or emotionally depriving world within which they developed has engendered in them the sophisticated skills that were required for adaptation. Thus to talk of deficit or absence of a capacity in such individuals is an oversimplification. Measures of global abilities may not yield a difference between these individuals and other groups. Efforts at going beyond clinical impression in terms of measurement have to take on board the situational specificity of the failure of reflective function.

We will return to the example of conduct disordered children, for whom we suggest that nonreflective internal working models may dominate behavior when an element of conflict is present within a relationship. Conflict, or rather its adaptive resolution, particularly calls for the perception both of the self and of the other in relation to the self, requiring the individual to reconcile his own legitimate claims with concern for the other (Killen \& Nucci, 1995). The abnormality of the early family environment of individuals with severe problems of conduct has been clearest in the context of normal conflicts (Patterson, 1982; Perry, Perry, \& Kennedy, 1992). Here the child with a vulnerable capacity for mentalization finds no affirmation of his intentional stance and fails to acquire the sense of ownership or inner endorsement of his actions essential for a sense of self-agency. Consequently his sense of autonomy becomes vulnerable 
and the importance of his original intention is exaggerated. The characteristics of oppositional defiant disorder (e.g., negativity, disobedience, aggression) may in part be seen as attempts at reasserting self-agency in a relationship where the connection between mental state and action within the self has been undermined by insensitive and coercive parenting.

Abnormalities of parenting represent but one route to limitations on reflective function. The child's biological vulnerabilities such as hyperactivity, attention problems, low impulse control, are all likely to obstruct the opportunity the child has for evolving a mentalized reflective model of conflict-related interpersonal situations. Within a dialectic or transactional model there is a bidirectional causality inherent to such biological vulnerabilities: They both provoke situations of conflict and place grave limitations on the child's capacity to acquire the flexibility needed for their adaptive handling. This may bear on the well demonstrated comorbidity between conduct disorders and hyperactivity or attention deficit disorder (Kazdin, 1995). Similarly, factors associated with early behavioral problems, such as poor parental adjustment (maternal aggression, suspiciousness, and mood disorder) (Shaw, Owens, Vondra, Keenan, \& Winslow, 1996; Zahn-Waxler, Ianotti, Cummings, \& Denham, 1990), and resources (marital dissatisfaction, parental conflict) (Block, Block, \& Gjerde, 1986; Campbell, Pierce, Moore, Marakovitz, \& Newby, 1996) may limit the parents' capacity to respond to the child in ways which promote a mentalizing model of self-other relationships.

The separation of action from intention undermines the emotional reaction an individual may have to the consequences of their actions since, as Hart and Killen (1995) pointed out, the acquisition of moral emotions requires that individuals are "active contributors to their own development, interpreting their world and making judgments that determine their actions in it" (p. 7). Subsequently, the predominant response to emotional situations will be a nonreflective one, readily disowned by the self. Naturally the absence of reflective function in such situations will give the appearance of rigidity to the person's behavior as if only a singular pattern of response were accessible. Furthermore, the response may frequently be in conflict with social norms because the tendency to take the perspective of others has been abandoned in that context and, consequently, the moral emotions used to make judgments about the consequences of actions and regulate behavior are absent. The absence of reflective function may further exaggerate an antisocial response by forcing the individual to see the other not as another intentional agent, but in nonhuman terms, as a body, as representing a social position or agency, or as a faceless member of a group.

Maltreatment, or more broadly trauma, is seen as interacting with the domain- and situation-specific restrictions upon reflective function at two levels. First, as we have argued, maltreatment presents the young child with a powerful emotional disincentive for taking the perspective of others, because of the actual hostility of the intentional stance of the abuser, as well as the constraints upon the self which an older person's failure to understand the child's budding intentionality imposes. Second, the child misses a protective factor, the capacity to understand traumatic interpersonal situations, which would be likely to limit their impact (Fonagy, Steele, Steele, Higgitt, \& Target, 1994). Thus, individuals traumatized by their family environment are vulnerable both in terms of the long-term maladaptive effect of their reaction to the trauma and in terms of their reduced resilience in the face of it. The predominantly nonmentalizing stance adopted in such situations therefore handicaps the individual and, if the vicious circle is unbroken, may come to dominate all interpersonal relationships. We believe that at this stage severe developmental psychopathology, in the adult entrenched personality disorder, is the likely consequence.

\section{References}

Ainsworth, M. D. S., Bell, S. M., \& Stayton, D. J. (1971). Attachment and exploratory behaviour of one year 
Ainsworth, M. D. S., Blehar, M. C., Waters, E., \& Wall, S. (1978). Patterns of attachment: A psychological study of the strange situation. Hillsdale, NJ: Erlbaum.

Alessandri, S. M. (1991). Play and social behaviours in maltreated preschoolers. Development and Psychopathology, 3, 191-206.

Alessandri, S. M. (1992). Mother-child interactional correlates of maltreated and nonmaltreated children's play behavior. Development and Psychopathology, 4, 257-270.

Astington, J. (1996). What is theoretical about the child's theory of mind?: A Vygotskian view of its development. In P. Carruthers \& P. K. Smith (Eds.), Theories of theories of mind (pp. 184-199). Cambridge: Cambridge University Press.

Astington, J., \& Jenkins, J. M. (1995). Theory of mind development and social understanding. Cognition and Emotion, 9, 151-165.

Baron-Cohen, S., \& Swettenham, J. (1996). The relationship between SAM and ToMM: Two hypotheses. In P. Carruthers \& P. K. Smith (Eds.), Theories of theories of mind (pp. 158-168). Cambridge: Cambridge University Press.

Baron-Cohen, S., Tager-Flusberg, H., \& Cohen, D. J. (1993). Understanding other minds: Perspectives from autism. Oxford: Oxford University Press.

Bartsch, K., \& Wellman, H. M. (1989). Young children's attribution of action to beliefs and desires. Child Development, 60, 946-964.

Baumrind, D. (1971). Current patterns of parental authority. Developmental Psychology Monographs, 4(1, Part 2).

Beebe, B., Lachmann, F., \& Jaffe, J. (1997). Mother-infant interaction structures and presymbolic self and object representations. Psychoanalytic Dialogues, 7, 133-182.

Beeghly, M., \& Cicchetti, D. (1994). Child maltreatment, attachment, and the self system: Emergence of an internal state lexicon in toddlers at high social risk. Development and Psychopathology, 6, 5-30.

Belsky, J., Garduque, L., \& Hrncir, E. (1984). Assessing performance, competence and executive capacity in infant play: Relations to home environment and security of attachment. Developmental Psychology, 20, 406-417.

Belsky, J., Rosenberger, K., \& Crnic, C. (1995). The origins of attachment security: "Classical" and contextual determinants. In S. Goldberg, R. Muir, \& J. Kerr (Eds.), John Bowlby's attachment theory: Historical, clinical and social significance (pp. 153-184). Hillsdale, NJ: Analytic Press.

Bidell, T. R., \& Fischer, K. W. (1994). Developmental transitions in children's early on-line planning. In M. M. Haith, J. B. Benson, R. J. Roberts, \& B. F. Pennington (Eds.), Development of future-oriented processes. Chicago: University of Chicago Press.

Bion, W. R. (1962). Learning from experience. London: Heinemann.

Bleiberg, E. (1984). Narcissistic disorders in children Bulletin of the Menninger Clinic, 48, 501-517.

Bleiberg, E. (1994). Borderline disorders in children and adolescents: The concept, the diagnosis, and the controversies. Bulletin of the Menninger Clinic, 58, 169196.

Block, J. H., Block, J., \& Gjerde, P. F. (1986). The personality of children prior to divorce. Child Development, 57, 827-840.

Bolton, D., \& Hill, J. (1996). Mind, meaning and mental disorder. Oxford: Oxford University Press.
Botterill, G. (1996). Folk psychology and theoretical status. In P. Carruthers \& P. K. Smith (Eds.), Theories of theories of mind (pp. 105-118). Cambridge: Cambridge University Press.

Bowlby, J. (1969). Attachment and loss, Vol. 1. Attachment. London: Hogarth Press and the Institute of Psycho-Analysis.

Bowlby, J. (1973). Attachment and loss, Vol. 2. Separation: Anxiety and anger. London: Hogarth Press and Institute of Psycho-Analysis.

Bowlby, J. (1980). Attachment and loss, Vol. 3. Loss: Sadness and depression. London: Hogarth Press and Institute of Psycho-Analysis.

Bracken, B. A. (Ed.). (1996). Handbook of self-concept: Developmental, social and clinical considerations. New York: Wiley.

Bretherton, I. (1991). Intentional communication and the development of an understanding of mind. In D. Frye \& C. Moore (Eds.), Children's theories of mind: Mental states and social understanding (pp. 271289). Hilldale, NJ: Erlbaum.

Bretherton, I., Bates, E., Benigni, L., Camaioni, L., \& Volterra, V. (1979). Relationships between cognition, communication, and quality of attachment. In E. Bates, L. Benigni, I. Bretherton, L. Camaioni, \& V. Volterra (Eds.), The emergence of symbols. New York: Academic Press.

Brownell, C. A., \& Kopp, C. B. (1991). Common threads, diverse solutions: Concluding commentary. Developmental Review, 11, 288-303.

Bruner, J. (1983). Child's talk: Learning to use language. Oxford: Oxford University Press.

Campbell, S. B., Pierce, E. W., Moore, G., Marakovitz, S., \& Newby, K. (1996). Boys' externalizing problems at elementary school age: Pathways from early behavior problems, maternal control and family stress. Development and Psychopathology, 8, 701-719.

Carlson, E., \& Sroufe, L. A. (1995). Contribution of attachment theory to developmental psychopathology. In D. Cicchetti \& D. J. Cohen (Eds.), Developmental Psychopathology. Vol. 1. Theory and methods (pp. 581-617). New York: Wiley.

Cassam, Q. (Ed.). (1994). Self-knowledge. Oxford: Oxford University Press.

Cassidy, J. (1994). Emotion regulation: Influences of attachment relationships. In N. A. Fox (Ed.), The development of attachment regulation. Monograph of the Society for Research in Child Development (Serial No. 240) (pp. 228-249).

Churchland, P. S. (1986). Neurophilosophy. Cambridge, MA: MIT Press.

Cicchetti, D., \& Beeghly, M. (1987). Symbolic development in maltreated youngsters: An organizational perspective. In D. Cicchetti \& M. Beeghly (Eds.), Atypical symbolic development. New directions for child development (Vol. 36, pp. 5-29). San Francisco: Jossey-Bass.

Cicchetti, D., \& Beeghly, M. (1990). The self in transition: Infancy and childhood. Chicago: University of Chicago Press.

Cicchetti, D., \& Toth, S. L. (Eds.). (1994). Disorders and dysfunctions of the self (Vol. 5). Rochester, NY: University of Rochester Press.

Cooley, C. H. (1964). Human Nature and the Social Or$\operatorname{der}$ (Rev. ed.). New York: Schocken Books (Original work published 1902).

Crittenden, P. A. (1992). Quality of attachment in the preschool years. Development and Psychopathology, 4, 209-241. 
Crittenden, P. M. (1988). Relationships at risk. In J. Belsky \& T. Nezworski (Eds.), Clinical implications of attachment (pp. 136-174). Hillsdale, NJ: Erlbaum.

Crittenden, P. M. (1990). Internal representational models of attachment relationships. Journal of Infant Mental Health, 11, 259-277.

Crittenden, P. M. (1994). Peering into the black box: A exploratory treatise on the development of self in young children. In D. Cicchetti \& S. L. Toth (Eds.), Rochester Symposium on Developmental Psychopathology: Vol. 5. Disorders and dysfunctions of the self (pp. 79-148). Rochester, NY: University of Rochester Press.

Crittenden, P. M., \& DiLalla, D. (1988). Compulsive compliance: The development of an inhibitory coping strategy in infancy. Journal of Abnormal Child Psychology, 16, 585-599.

Denham, S. A., Zoller, D., \& Couchoud, E. A. (1994). Socialization of preschoolers emotion understanding. Developmental Psychology, 30, 928-936.

Dennett, D. (1987). The intentional stance. Cambridge, MA: MIT Press.

Dennett, D. C. (1978). Brainstorms: Philosophical essays on mind and psychology. Montgomery, VT: Bradford.

Dias, M. G., \& Harris, P. L. (1990). The influence of the imagination on reasoning by young children. British Journal of Developmental Psychology, 8, 305-318.

Dunn, J. (1996). The Emanuel Miller Memorial Lecture 1995. Children's relationships: Bridging the divide between cognitive and social development. Journal of Child Psychology and Psychiatry, 37, 507-518.

Dunn, J., \& Brown, J. (1993). Early conversations about causality: Content, pragmatics, and developmental change. British Journal of Developmental Psychology, 11, 107-123.

Dunn, J., Brown, J., \& Beardsall, L. (1991a). Family talk about feeling states and children's later understanding of others' emotions. Developmental Psychology, 27, $448-455$.

Dunn, J., Brown, J., Somkowski, C., Telsa, C., \& Youngblade, L. (1991b). Young children's understanding of other people's feelings and beliefs: Individual differences and their antecedents. Child Development, 62, 1352-1366.

Elicker, J., Englund, M., \& Sroufe, L. A. (1992). Predicting peer competence and peer relationships in childhood from early parent-child relationships. In R. Parke \& G. Ladd (Eds.), Family-peer relationships: Modes of linkage (pp. 77-106). Hillsdale, NJ: Erlbaum.

Fischer, K. W., \& Ayoub, C. (1994). Affective splitting and dissociation in normal and maltreated children Developmental pathways for self in relationships. In D. Cicchetti \& T. H. Toth (Eds.), Rochester Symposium on Developmental Psychopathology: Vol. 5. Disorders and dysfunctions of the self (pp. 149-222). Rochester, NY: University of Rochester Press.

Fischer, K. W., \& Farrar, M. J. (1987). Generalisations about generalisation: How a theory of skill development explains both generality and specificity. International Journal of Psychology, 22, 643-677.

Fischer, K. W., Kenny, S. L., \& Pipp, S. L. (1990). How cognitive process and environmental conditions organize discontiuities in the development of abstractions. In C. N. Alexander, E. J. Langer, \& R. M. Oetzel (Eds.), Higher stages of development (pp. 162-187) New York: Oxford University Press.

Fischer, K. W., Knight, C. C., \& Van Parys, M. (1993). Analyzing diversity in developmental pathways: Methods and concepts. In W. Edelstein \& R. Case (Eds.), Constructivists approaches to development
Contributions to Human Development (Vol. 23, pp. 33-56). Basel, Switzerland: S. Karger.

Fischer, K. W., \& Pipp, S. L. (1984). Development of the structures of unconscious thought. In K. Bowers \& D. Meichenbaum (Eds.), The unconscious reconsidered (pp. 88-148). New York: Wiley.

Flavell, J. (1982). On cognitive development. Child Development, 53, 1-10.

Flavell, J. H., Flavell, E. R., \& Green, F. L. (1987). Young children's knowledge about the apparent-real and pretend-real distinction. Developmental Psychology, 23, 816-822.

Fónagy, I., \& Fónagy, J. (1987). Analysis of complex (integrated) melodic patterns. In R. Channon \& L. Shockey (Eds.), In honour of Ilse Lehiste (pp. 75-98). Dodrecht, The Netherlands: Foris.

Fonagy, P. (1995). Mental representations from an intergenerational cognitive science perspective. Infant Mental Health Journal, 15, 57-68.

Fonagy, P., Redfern, S., \& Charman, T. (1997). The relationship between belief-desire reasoning and a projective measure of attachment security (SAT). British Journal of Developmental Psychology, 15, 51-61.

Fonagy, P., Steele, H., Moran, G., Steele, M., \& Higgitt, A. (1991a). The capacity for understanding mental states: The reflective self in parent and child and its significance for security of attachment. Infant Mental Health Journal, 13, 200-217.

Fonagy, P., Steele, H., \& Steele, M. (1991b). Maternal representations of attachment during pregnancy predict the organization of infant-mother attachment at one year of age. Child Development, 62, 891-905.

Fonagy, P., Steele, H., Steele, M., \& Holder, J. (1997). Children securely attached in infancy perform better in belief-desire reasoning task at age five. Manuscript submitted to Child Development.

Fonagy, P., Steele, M., Steele, H., Higgitt, A., \& Target, M. (1994). Theory and practice of resilience. Journal of Child Psychology and Psychiatry, 35, 231-257.

Fonagy, P., Steele, M., Steele, H., Leigh, T., Kennedy, R., Mattoon, G., \& Target, M. (1995). Attachment, the reflective self, and borderline states: The predictive specificity of the Adult Attachment Interview and pathological emotional development. In S. Goldberg, R. Muir, \& J. Kerr (Eds.), Attachment theory: Social, developmental and clinical perspectives (pp. 233278). New York: Analytic Press.

Fonagy, P., Steele, M., Steele, H., \& Target, M. (1997). Reflective function manual for application to adult attachment interviews. London: University College London.

Fonagy, P., \& Target, M. (1995). Towards understanding violence: The use of the body and the role of the father. International Journal of Psycho-Analysis, 76, 487-502.

Fonagy, P., \& Target, M. (1996). Playing with reality: I. Theory of mind and the normal development of psychic reality. International Journal of Psycho-Analysis, 77, 217-234.

Gergely, G., \& Csibra, G. (1997). Teleological reasoning in infancy: The infant's naive theory of rational action. A reply to Premack and Premack. Cognition, 63, 227-233.

Gergely, G., Nadasdy, Z., Csibra, G., \& Biro, S. (1995). Taking the intentional stance at 12 months of age. Cognition, 56, 165-193.

Gergely, G., \& Watson, J. (1996). International Journal of Psycho-Analysis, 77, 1181-1212.

Goldman, A. (1989). Interpretation psychologized. Mind and Language, 4, 161-185. 
Goldman, A. (1993). Philosophical applications of cognitive science. Boulder, $\mathrm{CO}$ : Westview Press.

Gopnik, A. (1993). How we know our minds: The illusion of first-person knowledge of intentionality. Behavioral and Brain Sciences, 16, 1-14, 29-113.

Gopnik, A. (1996). Theories and modules; creation myths, developmental realities, and Neurath's boat. In P. Carruthers \& P. K. Smith (Eds.), Theories of theories of mind (pp. 169-183). Cambridge: Cambridge University Press.

Gopnik, A., \& Astington, J. W. (1988). Children's understanding of representational change and its relation to the understanding of false belief and the appearancereality distinction. Child Development, 59, 26-37.

Gordon, R. M. (1995). Simulation without introspection or inference from me to you. In T. Stone \& M. Davies (Eds.), Mental simulation: Evaluations and applications (pp. 101-119). Oxford: Blackwell.

Grossmann, K., Grossmann, K. E., Spangler, G., Suess, G., \& Unzner, L. (1985). Maternal sensitivity and newborn orienting responses as related to quality of attachment in Northern Germany. In I. Bretherton \& E. Waters (Eds.), Growing points in attachment theory and research. Monographs of the Society for Re search in Child Development, 50(1-2, Serial No. 209), (pp. 233-256).

Harris, P. (1996). Desires, beliefs, and language. In P. Carruthers \& P. K. Smith (Eds.), Theories of theories of mind (pp. 200-221). Cambridge: Cambridge University Press.

Harris, P. L. (1992). From simulation to folk psychology: The case for development. Mind and Language, 7, 120-144.

Harris, P. L., Kavanaugh, R. D., \& Meredith, M. (1994). Young children's comprehension of pretend episodes: The integration of successive actions. Child Development, 65, 16-30.

Hart, D., \& Killen, M. (1995). Introduction: Perspectives on morality in everyday life. In M. Killen \& D. Har (Eds.), Morality in everyday life (pp. 1-22). Cambridge: Cambridge University Press.

Harter, S., Marold, D. B., Whitesell, N. R., \& Cobbs, G. (1996). A model of the effects of parent and peer support on adolescent false self behavior. Child Development, 67.

Herman, J. (1992). Trauma and recovery. New York: Basic Books.

Hopkins, J. (1992). Psychoanalysis, interpretation, and science. In J. Hopkins \& A. Savile (Eds.), Psychoanalysis, mind and art: Perspectives on Richard Wollheim (pp. 3-34). Oxford: Blackwell.

Horowitz, M. J. (1995). Defensive control states and person schemas. In T. Shapiro \& R. N. Emde (Eds.), Research in psychoanalysis: Process, development, outcome (pp. 67-89). Madison, CT: International Universities Press.

Isabella, R., \& Belsky, J. (1991). Interactional synchrony and the origins of infant-mother attachment: A replication study. Child Development, 62, 373-384.

Isabella, R. A. (1993). Origins of attachment: Maternal interactive behavior across the first year. Child Development, 64, 605-621.

James, W. (1890). Principles of psychology. New York: Henry Holt \& Co.

James, W. (1892). Psychology: The briefer course. New York: Henry Holt \& Co.

Jenkins, J., \& Astington, J. W. (1996). Cognitive factors and family structure associated with theory of mind development in young children. Developmental Psychology, 32, 70-78.
Johnson, M. K., \& Multhaup, K. S. (1992). Emotion and MEM. In S. Christianson (Ed.), The handbook of emotion and memory: Research and theory (pp. 3366). Hillsdale, NJ: Erlbaum.

Kazdin, A. E. (1995). Conduct disorder in childhood and adolescence (2nd ed.). Thousand Oaks, CA: Sage.

Kernberg, O. F. (1982). Self, ego, affects and drives. Journal of the American Psychoanalytic Association, 30, 893-917.

Killen, M., \& Nucci, L. P. (1995). Morality, autonomy and social conflict. In M. Killen \& D. Hart (Eds.), Morality in everyday life (pp. 52-86). Cambridge: Cambridge University Press.

Leslie, A. M. (1987). Pretense and representation: The origins of "Theory of Mind." Psychological Review, 94, 412-426.

Leslie, A. M. (1994). TOMM, ToBy, and agency: Core architecture and domain specificity. In L. Hirschfeld \& S. Gelman (Eds.), Mapping the mind: Domain specificity in cognition and culture (pp. 119-148). New York: Cambridge University Press.

Lillard, A. S. (1993). Pretend play skills and the child's theory of mind. Child Development, 64, 348-371.

Londerville, S., \& Main, M. (1981). Security of attachment, compliance and maternal training method in the second year of life. Developmental Psychology, 17, 289-299.

Luborsky, L., \& Luborsky, E. (1995). The era of measures of transference: The CCRT and other measures. In T. Shapiro \& R. Emde (Eds.), Research in psychoanalysis (pp. 329-351).

Main, M., \& Cassidy, J. (1988). Categories of response to reunion with the parent at age 6: Predictable from infant attachment classifications and stable over a 1-month period. Developmental Psychology, 24, 415-426.

Main, M., Kaplan, N., \& Cassidy, J. (1985). Security in infancy, childhood, and adulthood: A move to the level of representation. In I. Bretherton \& E. Waters (Eds.), Growing points in attachment theory and research. Monographs of the Society for Research in Child Development, 50 (pp. 66-104).

Mandler, G. (1985). Cognitive Psychology. An Essay in Cognitive Science. Hillsdale, NJ: Erlbaum.

Meins, E., Fernyhough, C., Russel, J., \& Clark-Carter, D. (in press). Security of attachment as a predictor of symbolic and mentalising abilities: A longitudinal study. Social Development.

Mele, A. R. (1992). Springs of action: Understanding intentional behaviour. New York: Oxford University Press.

Meltzoff, A. (1993). The role of imitation in understanding persons and developing a theory of mind. In $\mathrm{S}$. Baron-Cohen, H. Tager-Flusberg, \& D.Cohen (Eds.), Understanding Other Minds: Perspectives from Autism. New York: Oxford University Press.

Morton, J., \& Frith, U. (1995). Causal modeling: A structural approach to developmental psychology. In D. Cicchetti \& D. J. Cohen (Eds.), Developmental psychopathology: Vol. 1. Theory and methods (pp. 357390). New York: John Wiley.

Moss, E., Parent, S., \& Gosselin, C. (1995). Attachment and theory of mind: Cognitive and metacognitive correlates of attachment during the preschool period. $\mathrm{Pa}-$ per presented at the biennial meeting of the Society for Research in Child Development, Indianapolis, Indiana, March-April.

Mundy, P., \& Hogan, A. (1994). Intersubjectivity, joint attention, and autistic developmental pathology. In D. Cicchetti \& S. L. Toth (Eds.), Rochester Symposium on Developmental Psychopathology: Vol. 5. Disor- 
ders and dysfunctions of the self (pp. 1-30). Rochester, NY: University of Rochester Press.

Neisser, U. (1991). Two perceptually given aspects of the self and their development. Developmental Review, 11, 197-209.

Noam, G. G. (1990). Beyond Freud and Piaget: Biographical world-Interpersonal self. In T. E. Wren (Ed.), The moral domain (pp. 360-399). Cambridge, MA: MIT Press.

Park, K., \& Waters, E. (1989). Security of attachment and preschool friendships. Child Development, 60, 10761081.

Patterson, G. R. (1982). Coercive family processes. Aegean, OR: Castilia Publishing Co.

Perner, J., Leekam, S., \& Wimmer, H. (1987). Threeyear-olds' difficulty in understanding false belief: Cognitive limitation, lack of knowledge, or pragmatic misunderstanding? British Journal of Developmental Psychology, 5, 125-137.

Perner, J., Ruffman, T., \& Leekman, S. R. (1994). Theory of mind is contagious: You catch it from your sibs. Child Development, 65, 1228-1238.

Perry, D. G., Perry, L. C., \& Kennedy, E. (1992). Conflict and the development of antisocial behavior. In C. U. Shantz \& W. W. Hartup (Eds.), Conflict in child and adolescent development (pp. 301-329). Cambridge: Cambridge University Press.

Rogers, S., \& Pennington, B. (1991). A theoretical approach to the deficits in infantile autism. Development and Psychopathology, 3, 137-162.

Ruffman, T., Perner, J., Naito, M., Parkin, L., \& Clements, W. (in press). Older (but not younger) siblings facilitate false belief understanding. Child Development.

Schacter, D. L. (1992). Understanding implicit memory: A cognitive neuroscience approach. American Psychologist, 47, 559-569.

Schneider-Rosen, K., \& Cicchetti, D. (1984). The relationship between affect and cognition in maltreated infants: Quality of attachment and the development of visual self-recognition. Child Development, 55, 648658.

Schneider-Rosen, K., \& Cicchetti, D. (1991). Early self-knowledge and emotional development: Visual self-recognition and affective reactions to mirror selfimage in maltreated and non-maltreated toddlers. Developmental Psychology, 27, 481-488.

Segal, G. (1996). The modularity of theory of mind. In P. Carruthers \& P. K. Smith (Eds.), Theories of theories of mind. Cambridge: Cambridge University Press.

Shaw, D. S., Owens, E. B., Vondra, J. I., Keenan, K., \& Winslow, E. B. (1996). Early risk factors and pathways in the development of early disruptive behavior problems. Development and Psychopathology, 8 , 679-699.

Slade, A. (1987). Quality of attachment and early symbolic play. Developmental Psychology, 17, 326-335.

Slade, A., Belsky, J., Aber, L., \& Phelps, J. L. (in press). Maternal Representations of their toddlers: Links to adult attachment and observed mothering. Developmental Psychology.

Smith, P. K. (1996). Language and the evolution of mindreading. In P. Carruthers \& P. K. Smith (Eds.), Theories of theories of mind (pp. 344-354). Cambridge: Cambridge University Press.

Spangler, G., \& Grossman, K. E. (1993). Biobehavioral organization in securely and insecurely attached infants. Child Development, 64, 1439-1450.
Sroufe, L. A. (1990). An organizational perspective on the self. In D.Cicchetti \& M.Beeghly (Eds.), The self in transition: Infancy to childhood (pp. 281-307). Chicago: University of Chicago Press.

Sroufe, L. A. (1996). Emotional development. New York: Cambridge University Press.

Steele, H., Steele, M., \& Fonagy, P. (1996). Associations among attachment classifications of mothers, fathers, and their infants: Evidence for a relationship-specific perspective. Child Development, 67, 541-555.

Stern, D. N. (1985). The interpersonal world of the infant: A view from psychoanalysis and developmental psychology. New York: Basic Books.

Target, M., \& Fonagy, P. (1996). Playing with reality. II: The development of psychic reality from a theoretical perspective. International Journal of Psycho-Analysis, 77, 459-479.

Tronick, E. (1989). Emotions and emotional communication in infants. American Psychologist, 44, 112-119.

van der Kolk, B. (1994). The body keeps the score: Memory and the evolving psychobiology of post-traumatic stress. Harvard Review of Psychiatry, 1, 253-265.

van IJzendoorn, M. H. (1995). Adult attachment representations, parental responsiveness, and infant attachment: A meta-analysis on the predictive validity of the Adult Attachment Interview. Psychological Bulletin, 117, 387-403.

van IJzendoorn, M. H., Juffer, F., \& Duyvesteyn, M. G. C. (1995). Breaking the intergenerational cycle of insecure attachment: A review of the effects of attachment-based interventions on maternal sensitivity and infant security. Journal of Child Psychology and Psychiatry, 36, 225-248.

van IJzendoorn, M. H., Kranenburg, M. J., Zwart-Woudstra, H. A., Van Busschbach, A. M., \& Lambermon, M. W. E. (1991). Parental attachment and children's socio-emotional development: Some findings on the validity of the Adult Attachment Interview in the Netherlands. International Journal of Behavioral Development, 14, 375-394.

Vygotsky, L. S. (1967). Play and its role in the mental development of the child. Soviet Psychology, 5, 6-18.

Ward, M. J., \& Carlson, E. A. (1995). Associations among Adult Attachment representations, maternal sensitivity, and infant-mother attachment in a sample of adolescent mothers. Child Development, 66, 69-79.

Wellman, H. M. (1993). Early understanding of mind: The normal case. In S. Baron-Cohen, H. TagerFlusberg, \& D. J. Cohen (Eds.), Understanding other minds: Perspectives from autism (pp. 40-58). New York: Oxford University Press.

Winnicott, D. W. (1960). Ego distortion in terms of true and false self, The maturational process and the facilitating environment (pp. 140-152). New York: International Universities Press.

Winnicott, D. W. (1965). The maturational process and the facilitating environment. London: Hogarth Press.

Wollheim, R. (1995). The mind and its depths. Cambridge, MA: Harvard University Press.

Youngblade, L., \& Dunn, J. (1995). Individual differences in young children's pretend play with mother and sibling: Links to relationships and understanding of other people's feelings and beliefs. Child Development, 66, 1472-1492.

Zahn-Waxler, C., Ianotti, R. J., Cummings, E. M., \& Denham, S. (1990). Antecedents of problem behavior in children of depressed mothers. Development and Psychopathology, 2, 271-292. 